\title{
A mammalian fossil from the Dingqing Formation in the Lunpola Basin, northern Tibet, and its relevance to age and paleo-altimetry
}

\author{
DENG Tao ${ }^{1 *}$, WANG ShiQi ${ }^{1}$, XIE GuangPu $^{2}$, LI Qiang $^{1}$, HOU SuKuan $^{1} \&$ SUN BoYang ${ }^{1,3}$ \\ ${ }^{1}$ Key Laboratory of Evolutionary Systematics of Vertebrates, Institute of Vertebrate Paleontology and Paleoanthropology, Chinese Academy of \\ Sciences, Beijing 100044, China; \\ ${ }^{2}$ Gansu Provincial Museum, Lanzhou 730050, China; \\ ${ }^{3}$ Graduate University of the Chinese Academy of Sciences, Beijing 100049, China
}

Received April 15, 2011; accepted July 26, 2011; published online September 27, 2011

\begin{abstract}
The distal extremity of a rhinocerotid humerus from the upper part of the Dingqing Formation at the Lunbori locality in Baingoin County, northern Tibet, is the first mammalian fossil found in Cenozoic deposits of the Lunpola Basin. The medial condyle of the distal trochlea of the humerus specimen from Lunbori gradually contracts from medially to laterally. The margin of the medial surface of the medial condyle is not prominent, the well-developed medial epicondyle strongly extends posteriorly, and is divided from the articular facet of the medial condyle by a groove; all of which are characteristic for the Rhinocerotidae. The medial condyle is wide at the bottom and narrow at the top. The medial collateral ligament fossa is relatively shallow, and the medial collateral ligament tubercle is very weak. The medial part of the upper margin of the medial condyle smoothly connects to the bony surface above, but there is no clear boundary between them. All of these characteristics are identical with those of Plesiaceratherium. These comparisons imply that the Lunbori specimen is closest to Plesiaceratherium gracile in the Shanwang Fauna from Linqu, Shandong Province, in size and morphology. Thus, its age is suggested to be the late Early Miocene (Shanwangian Age), about 18-16 Ma. Discovery of the rhinocerotid fossil suggests that the upper part of the Dingqing Formation deposited in the Neogene. While adjusting to paleo-temperatures of the Early Miocene, a paleo-ecosystem reconstruction indicates that the paleoelevation was close to $3000 \mathrm{~m}$ in the Lunpola Basin during this time.
\end{abstract}

Tibetan Plateau, Lunpola Basin, paleo-altimetry, Miocene, Dingqing Formation, Rhinocerotidae

Citation: Deng T, Wang S Q, Xie G P, et al. A mammalian fossil from the Dingqing Formation in the Lunpola Basin, northern Tibet, and its relevance to age and paleo-altimetry. Chin Sci Bull, 2012, 57: 261-269, doi: 10.1007/s11434-011-4773-8

The Rhinocerotidae is the family containing rhinoceroses whose characteristic feature is a chisel/tusk combination of the upper first incisor and the lower second incisor. The Rhinocerotidae reached their highest diversity in the Miocene, during which time they were widely distributed in Eurasia, North America, and Africa [1]. The rhinocerotids were herbivores, and most lived in tropical or temperate areas, but a few species, such as the woolly rhino (genus Coelodonta) lived in cold zones [2]. Rhinocerotid fossils are important standard fossils with strict chronological significance for the Cenozoic, and are important indicators of the

*Corresponding author (email: dengtao@ivpp.ac.cn) ecosystems inhabited by mammalian faunas.

The Lunpola Basin is located on the southern and northern sides of the boundary between Baingoin County and the Shuanghu Special District in northern Tibet. The basin has well-developed Cenozoic strata and an average elevation of about $4700 \mathrm{~m}$ a.s.l. The total thickness of Cenozoic deposits in the Lunpola Basin is over $4000 \mathrm{~m}$, and consists of the Niubao Formation in the lower part and the Dingqing Formation in the upper part. The Tertiary age of these deposits is not in question, but there have been different opinions about their ages at the epoch or series levels [3-6]. Previously, the lack of mammalian fossils strictly constrained the subdivision and correlation of these Cenozoic strata. The 
paleontological evidence to identify ages in this basin has depended mainly on sporopollens and ostracods. Estimations of the paleo-elevation of the Lunpola Basin have been very different using these datasets. During the deposition of the Dingqing Formation, the lowest estimate has been reported to be about $1000 \mathrm{~m}$ [7], but the highest published estimate is $4500 \mathrm{~m}$ [8]. Guided by previous reports [9], in 2009 and 2010, we carried out an extensive and detailed investigation of the stratigraphy and a survey for vertebrate fossils. We found more beds and specimens of fish fossils in the Dingqing Formation. Most importantly, we found a rhinocerotid fossil in the Dingqing Formation, which is significant for age determination and the paleo-altimetry estimation. In this paper, we present and discuss our study of this mammalian fossil from the Lunpola Basin.

\section{Geological setting}

The Lunpola Basin is a Cenozoic terrestrial basin, which developed on Yanshanian folded basement rocks. Its formation and evolution are related to the movement history of the Bangong-Nujiang deep fault. Relative right-lateral wrench movement of this fault caused production of the NNE-SSW oriented tensile stress in this area, where a strike-slip extensional basin was formed [10].

The Lunpola Basin is elongated, beginning in the east near Dongqiao and ending at Duojialing to the north of Siling Co (lake) in the west. It has an E-W length of about $200 \mathrm{~km}$, a N-S width of about $15-20 \mathrm{~km}$, and an area of over $4000 \mathrm{~km}^{2}$. The names of the Dingqing and Niubao formations are derived from the Dingqing and Niubao beds that were nominated by the Qinghai Petroleum Survey Team in 1957. The Dingqing Formation is widely distributed in the central and eastern parts of the Lunpola Basin, and consists of a series of greenish-gray mudstones and shale alternating beds of sandstones and oil shales, with a thickness of 300-1100 m. It bears rich animal and plant fossils, such as ostracods, gastropods, insects, fishes, and sporopollens. The Niubao Formation is distributed throughout the entire basin. It is a series of red clastic rocks alternating beds of grayish-green mudstones and sandstones, with a thickness of 700-950 m, bearing comparatively fewer fossils, including ostracods, sporopollens, and charophytes [6].

The Tertiary deposits of the Lunpola Basin were first discovered and confirmed in 1955 [11], and were subdivided into three beds. In 1975, the strata of the Lunpola Basin were first subdivided based on fossils into four formations, the Diou, Niubao, Dingqing, and Lunpola formations of the Eocene, Oligocene, Miocene, and Pliocene, respectively [3]. In 1982, based on ostracod fossils, the Niubao Formation was referred to the Eocene, the Dingqing Formation was referred to the Oligocene, the Diou Formation was included in the Niubao Formation, and the Lunpola Formation was included in the Dingqing Formation [4]. In 1983, the upper member of the Dingqing Formation was referred to the Pliocene, the middle member to the Miocene, and the lower member to the Late Oligocene, and the Niubao Formation was referred to the Eocene-Oligocene [6]. Recently completed geological mapping of the Tibetan Plateau indicates that the Niubao Formation has four ostracod assemblages from its base to top. These are the Limnocythere-Eucypris, LimnocythereCypris-Cyprinotus, Limnocythere-Cypris-Eucypris-Candona, and Cypinotus-Candona assemblages from the Eocene [12]. The Dingqing Formation has two ostracod assemblages from its base to top, the Austrocypris-Cyprinotus-Pelocypris and Ilyocypris-Limnocythere assemblages [13] from the Oligocene [14].

The Lunbori area is located in the center of Lunpola Basin (Figure 1) and tectonically belongs to the NakacoDongkaco central landmass. This tectonic unit is a rigid landmass that is situated between the southern and northern zones of the Bangong-Nujiang suture, which consists mainly of the Mesozoic Jurassic Jienu Group and Early Cretaceous Qushenla Formation, overlain by the Dingqing Formation.

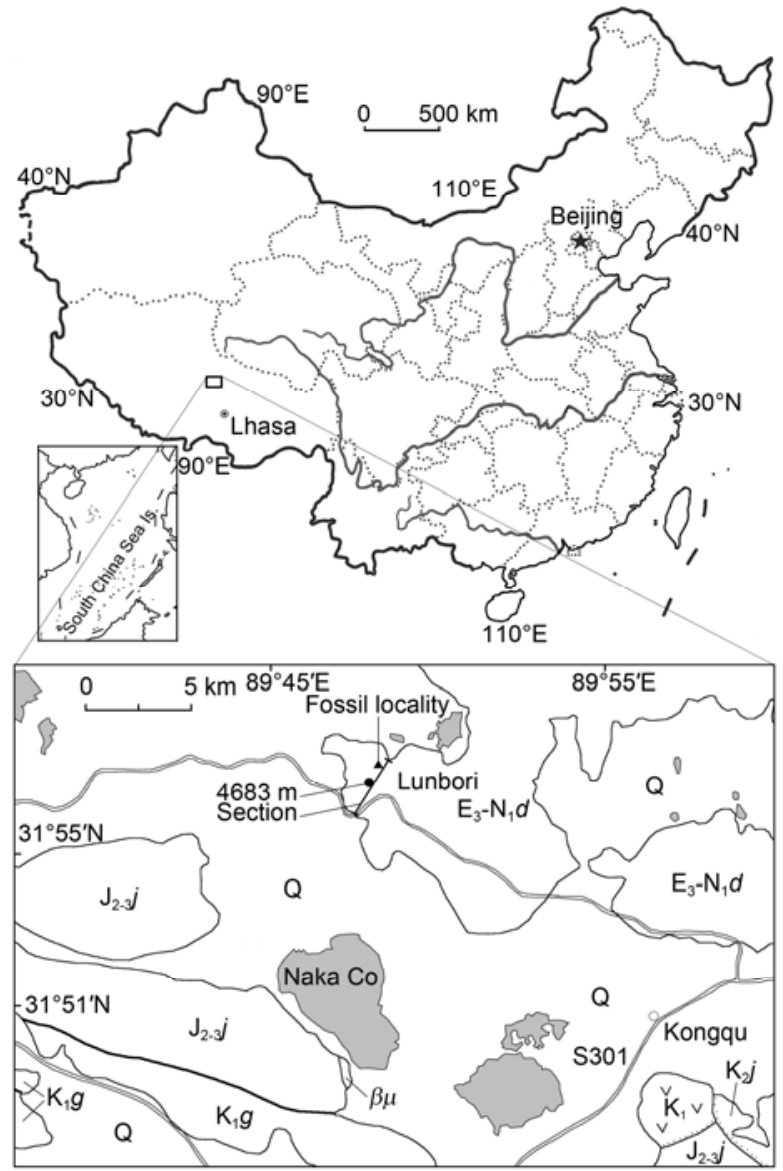

Figure 1 Geological map and location of the fossil site surround Lunbori in the Lunpola Basin. $\mathrm{K}_{2} j$, Upper Cretaceous Jingzhushan Fm.; $\mathrm{J}_{2^{-}-3} j$, Middle-Upper Jurassic Jienu Group; $\mathrm{K}_{1}$, Lower Cretaceous volcanic rock; $\mathrm{K}_{1} g$, Lower Cretaceous Guiya Fm.; $\mathrm{E}_{3}-\mathrm{N}_{1} d$, Oligocene-Miocene Dingqing Fm.; $\mathrm{Q}$, Quaternary; $\beta \mu$, diabase dike. Modified from [12]. 
The tectonics in this area are dominated by faults that developed parallel to the southern zone of the BangongNujiang suture, superimposed multiple times with a successive activation, and expressed mainly as clockwise rightlateral shearing [12].

In this study, the total thickness of the section of the Dingqing Formation at Lunbori is $989.5 \mathrm{~m}$. Layers 1-4 alternated between gray thick- to huge thick-bedded shale and thin-bedded limestones, banded gray oily shale, brownish yellow shale, and light brown silty marlites, with rich plant and insect fossils in the middle part and a thickness of $109.4 \mathrm{~m}$. Layers 5-9 alternated between gray shale and brownishgray paper-thin oil shale, containing well-preserved fish, insect, and plant fossils, as well as horizons of banded brownishyellow thin-bedded siderites, with a thickness of $583.7 \mathrm{~m}$. Layers 10-18 alternated between brownish-gray thickly bedded paper-thin oil shale and thickly bedded gray shale, banded reddish-brown, gray, and light yellow massive mudstones bearing bivalve, fish, and mammal fossils in the upper part, and brown thin-bedded silty mudstones and thinbedded tuffaceous sandstones with a thickness of $209.3 \mathrm{~m}$. Layers 19-28 constituted gray thin-bedded mudstones, marlite, and gray thin-bedded shale, banded brownish-grey paperthin oil shale and light yellow thin-bedded marlites with a thickness of $87.1 \mathrm{~m}$ (Figure 2). The mammalian fossil reported in this paper was collected from the reddish massive mudstones of layer 17 , which comprises the distal extremity of the left humerus of a rhinocerotid. This fossil locality is situated on the northern side of Lunbori Hill (Figure 3), with geographic coordinates of $31^{\circ} 57^{\prime} 27.6^{\prime \prime} \mathrm{N}$ and $89^{\circ} 47^{\prime} 55.7^{\prime \prime} \mathrm{E}$, and an elevation of $4624 \mathrm{~m}$. There is also a great number of scattered fish bone fossils and many bivalve fossils at this location.

\section{Systematic paleontology}

\author{
Class Mammalia Linnaeus, 1758 \\ Order Perissodactyla Owen, 1848 \\ Family Rhinocerotidae Owen, 1845 \\ Subfamily Aceratheriinae Dollo, 1885 \\ Genus Plesiaceratherium Young, 1937 \\ Plesiaceratherium sp.
}

(i) Material. The medial part of the distal extremity of a left humerus with the complete medial condyle and the residual epicondyle (Figure 4(a)), IVPP (Institute of Vertebrate Paleontology and Paleoanthropology, Chinese Academy of Sciences) catalogue number V 18082. This specimen is strongly lithified. It is yellowish brown, with black spots on the surface, and a black film could be seen in the broken section. Due to corrosion from plant alkaloids in grass roots, white root prints were evident on the partial surface, which are similar to those in preserved mammalian fossils from the Bulong Basin in Biru County, Tibet [15].

(ii) Description. The medial condyle of the distal trochlea
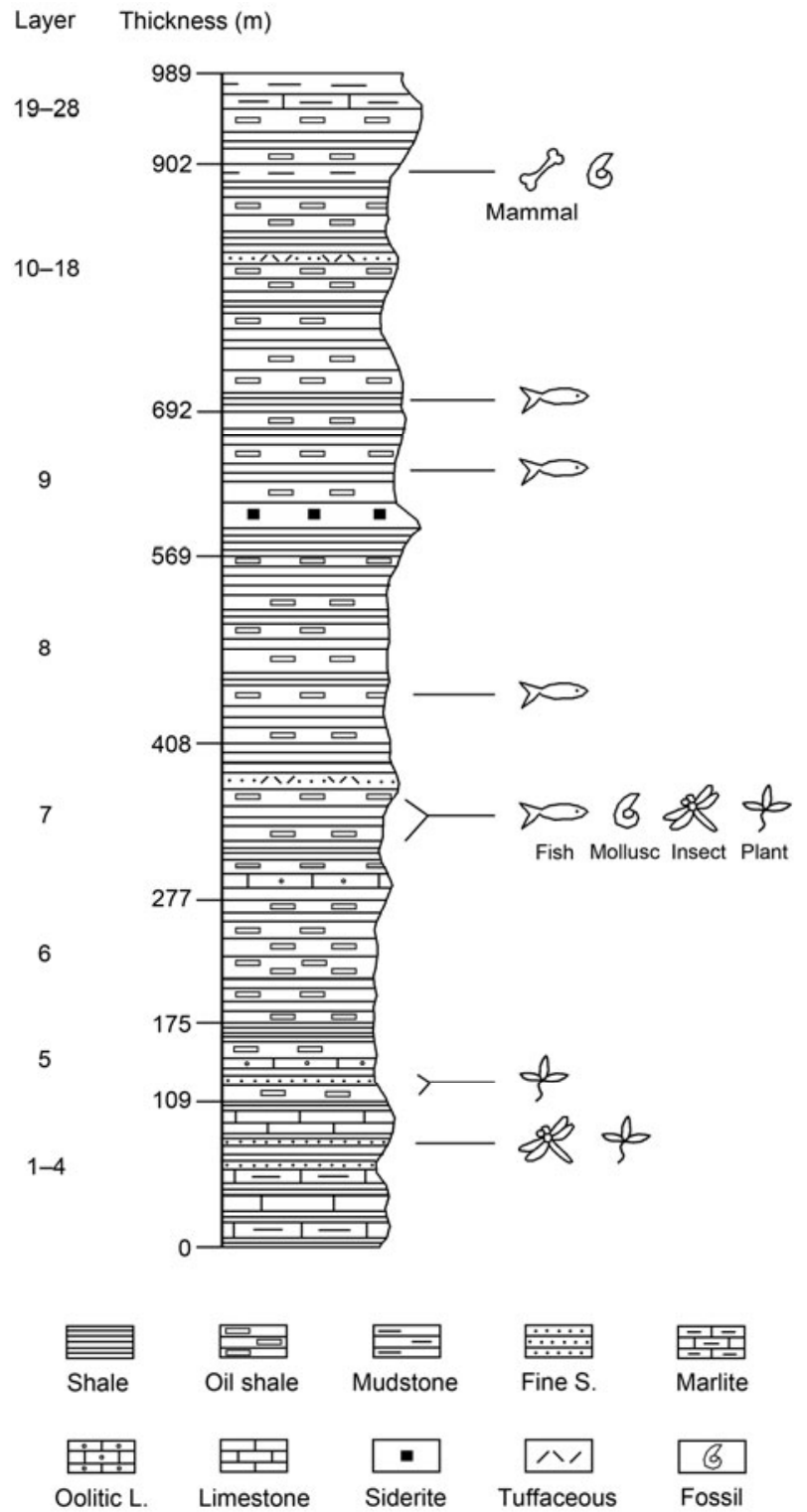

Figure 2 Columnar section at Lunbori in the Lunpola Basin. S, sandstone; $\mathrm{L}$, limestone.

of the humerus is a cone that is gradually constricted medially to laterally. Its articular surface lacks a secondary separation, which articulates with the glenoid fossa of the radius and the semilunar notch of the ulna (Figure 4(a3)). In anterior view, the medial condyle is wide at the lower end and narrow at top, so that its upper part is inclined to the midline of the shaft. The medial part of the upper margin of the medial condyle is smoothly connected to the bony surface above and lacks a prominent edge (Figure 4(a2)). In medial view, the residual part of the epicondyle implies that it is well-developed. The lower margin of the epicondyle is clearly higher than the medial surface of the medial condyle, and the anterior end of the former penetrates into the lower part of the latter. Thus, the connection between the anterior end of the medial epicondyle and the posterior end of the 


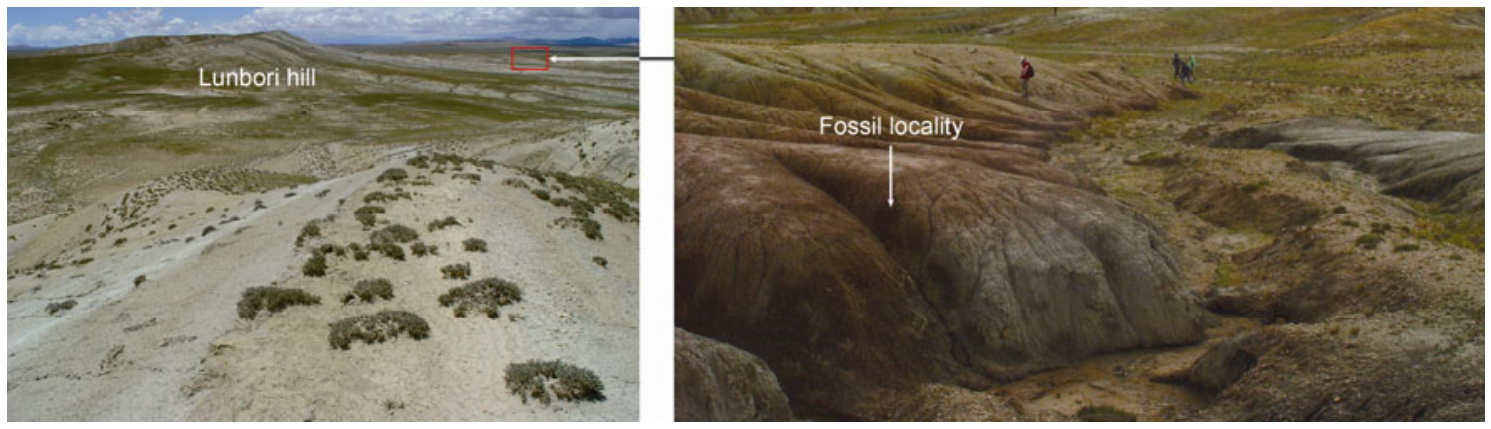

Figure 3 Lunbori fossil locality in the Lunpola Basin.

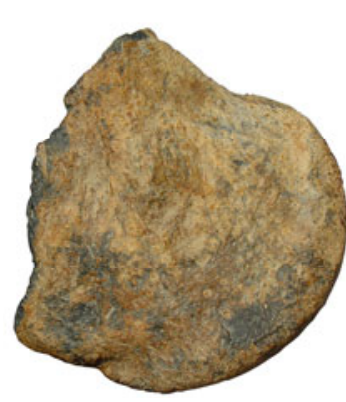

(a1)

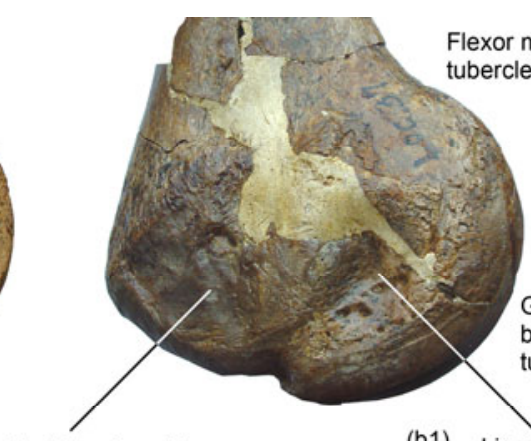

(b1)

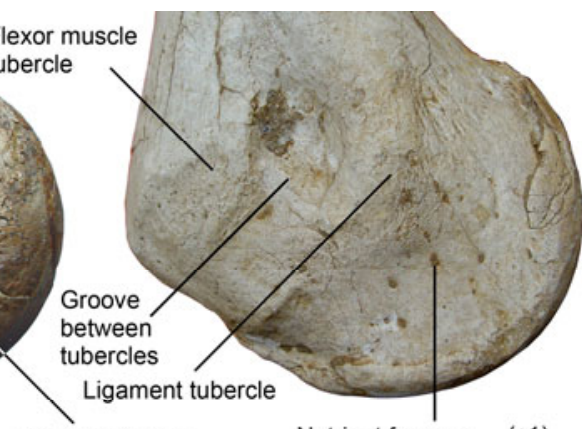

Nutrient foramen
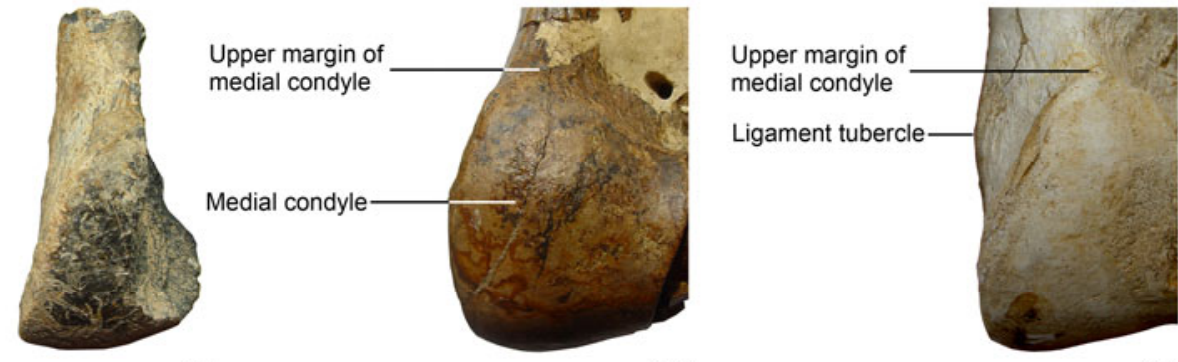

(a2)

(b2)

(c2)

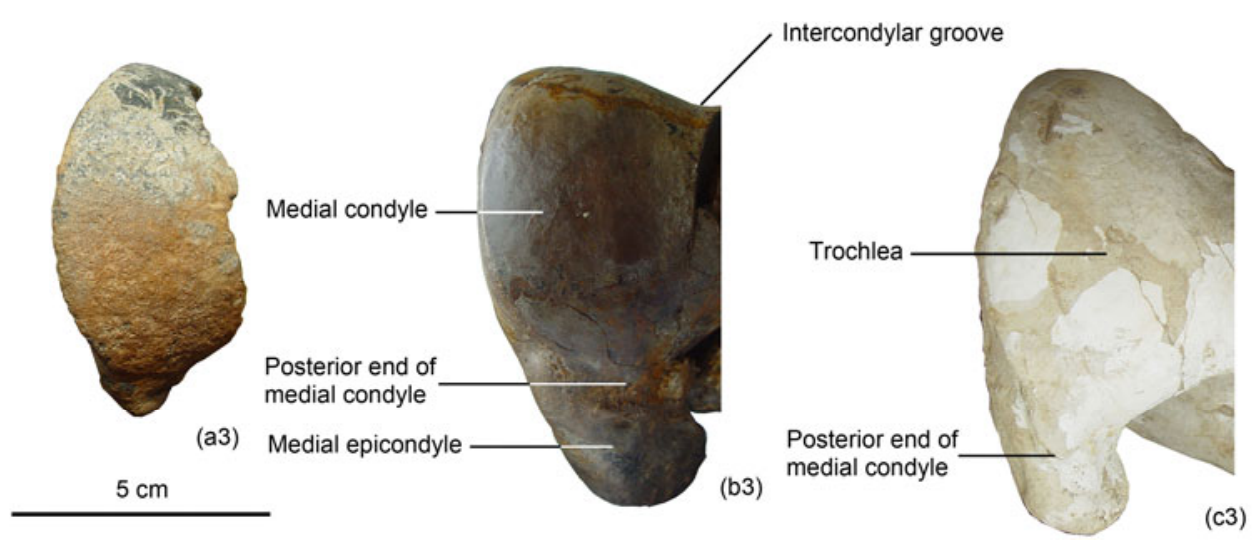

Figure 4 Comparison between the Lunbori specimen and the distal extremities of the humeri of Plesiaceratherium gracile and Chilotherium wimani. a, Plesiaceratherium sp., V 18082 from Lunbori, Baingoin, Tibet; b, Plesiaceratherium gracile, RV 37065 from Shanwang, Linqu, Shandong; c, Chilotherium wimani, HMV 0449 from Houshan, Guanghe, Gansu Province. 1, Medial view; 2, anterior view; 3, distal view.

medial condyle forms a nearly horizontal groove. The marginal area of the medial surface of the medial condyle is a rough crescent with a width of $7 \mathrm{~mm}$ at the middle, the two ends of which disappear at the upper and lower ends of the medial condyle. There are some minute rounded pits on the middle and lower parts of the medial surface of the medial 
condyle, which are the openings of the nutrient foramens with a maximum diameter of $1 \mathrm{~mm}$. The medial collateral ligament fossa is relatively shallow, with an unclear border and a gradual transition to the bony surface. In this fossa, there is a fine crest oblique from anterosuperior to posteroinferior, with a length of $12 \mathrm{~mm}$, which coincides with the connecting line between the upper and lower ends of the medial condyle. The center of the medial collateral ligament fossa is situated at the midpoint of this line. The medial collateral ligament tubercle is weakly prominent and located above the collateral ligament fossa, also with a central fine crest parallel to the crest in the fossa and equal to the length of the latter. Behind the collateral ligament tubercle is a vertical, wide, and shallow depression, which separates the collateral ligament tubercle from another tubercle attached to the superficial digital flexor muscle on the medial surface of the medial epicondyle (Figure 4(a1)). In distal view, the medial condyle does not extend posteriorly, and its posterior end does not reach the anteroposterior midline of the medial epicondyle (Figure 4(a3)). The maximum diameter of the medial condyle is $67.5 \mathrm{~mm}$.

(iii) Comparison. The Lunbori specimen is different from artiodactyl humeri. In an artiodactyl humerus, the central part of the medial condyle of the distal trochlea is not lower than the medial part so that the medial condyle is not constricted or only weakly constricted, and even slightly expanded from medially to laterally. For example, in bovids, the central diameter of the medial condyle of the distal trochlea is larger than the medial one [16].

In perissodactyl humeri, the medial condyle of the distal trochlea in horses has the same anteroposterior diameter or is only slightly enlarged from medially to laterally, but abruptly becomes small near the intercondylar groove, and is crossed by a sagittal groove [17]. In tapirs, the medial surface of the medial condyle is convex as a whole, and the medial epicondyle is strongly developed and is transversely very thick, with an anteroposterior length close to that of the medial condyle. In chalicotheres, the medial condyle has an asymmetric constriction from medially to laterally, the anterior part of the medial margin has a small articular facet. The medial epicondyle is transversely wide, but anteroposteriorly short $[18,19]$. In titanotheres, the lower margin of the medial epicondyle strongly rises, with a relatively large distance from the lower margin of the medial condyle, although the anterior part of the medial margin of the medial condyle in some titanothere forms is distinctly concave $[20,21]$. In the humeri of rhinoceroses, the medial condyle of the distal trochlea is a comparatively symmetric cone constricted gradually from medially to laterally, and lacks a sagittal groove or ridge to subdivide it [16]. The morphologic features of the Lunbori specimen are identical to those of rhinoceroses.

The Rhinocerotoidea is a group of perissodactyls with the highest diversity of species and habitats and is generally divided into three families (i.e. Hyracodontidae, Amyno- dontidae, and Rhinocerotidae [22]).

In Imequincisoria sp. [23], for example, the margin of the medial surface of the medial condyle of the distal trochlea forms a wide crescent ridge for the hyracondot's humerus. The medial epicondyle weakly extends posteriorly and inferiorly. The medial surface is very uneven. The medial collateral ligament fossa and tubercle are marked and located above the connecting line between the upper and lower ends of the medial condyle. The lower margin of the medial epicondyle has a continuous transition to the lower margin of the medial condyle, without a distinct boundary between them in medial view. The depression between the medial collateral ligament tubercle and the superficial digital flexor muscle tubercle is relatively large. The giant rhinos, which were included in the Hyracodontidae, have the same features, such as the humerus of Juxia sharamurenensis [24].

In Gigantamynodon promises [25], for example, the medial epicondyle of the distal extremity for the amynodont's humerus is less developed and steeply inclined posterosuperiorly, and its lower margin has a gradual transition to the lower margin of the medial condyle in medial view. The small and deep collateral ligament fossa is tightly situated under the highly raised collateral ligament tubercle that is a triangular pyramid, and the former is located at the connecting line between the upper and lower ends of the medial condyle. The crescent ridge on the medial surface of the medial condyle is strongly prominent. The tubercle that is attached to the superficial digital flexor muscle is a prominent crest that extends to the posterior margin of the medial surface.

In the humeri of the Rhinocerotidae, the margin of the medial surface of the medial condyle is not prominent and the medial epicondyle is well developed and strongly extends posteriorly with a groove to divide it from the articular surface of the medial condyle. Clearly, the Lunbori specimen belongs to the Rhinocerotidae. Comparing with different taxa within the Rhinocerotidae, the Lunbori specimen is almost identical to the distal extremity of the humerus of Plesiaceratherium gracile (Figure 4(b)) from the late Early Miocene Shanwang Fauna from Linqu County, Shandong Province. The above-mentioned features of the distal extremity of the Lunbori humerus can be seen in the specimen IVPP RV 37065 of $P$. gracile. In $P$. gracile, for example, the upper part of the medial condyle is inclined to the midline of the shaft, and its upper margin is smoothly connected to the bony surface. The lower margin of the epicondyle is clearly higher than the medial surface of the medial condyle, and the anterior end of the former penetrates into the lower part of the latter, so that their connection forms a nearly horizontal groove. On the medial surface of the medial condyle, the crescent surface is marked, and the nutrient foramens are rich. The medial collateral ligament fossa has no a clear border, and the collateral ligament tubercle is weakly prominent. The depression is wide and shallow 
between the collateral ligament and the superficial digital flexor muscle tubercles. The medial condyle does not extend posteriorly. For the humerus (IVPP RV 37065) of $P$. gracile, the maximum diameter of the medial condyle is $67 \mathrm{~mm}$, which is also close to that of the Lunbori specimen $(67.5 \mathrm{~mm})$. Minor differences are the more marked collateral ligament fossa and the smoother medial surface of the medial condyle in $P$. gracile (Figure $4(\mathrm{~b} 1)$ ) than in the Lunbori specimen. Thus, we identified the Lunbori specimen as Plesiaceratherium sp.

Within the Rhinocerotidae, many medium-sized forms are similar to the Lunbori specimen in size, but different in morphology. In the humerus of Chilotherium wimani, for example, the lower margin of the medial epicondyle of the distal extremity is strongly inclined posterosuperiorly, and the anterior margin does not reach the posterior part of the medial condyle of the trochlea in medial view. There is no notch or groove between the epicondyle and the condyle. The collateral ligament tubercle is relatively prominent, but the collateral ligament fossa is very weak (Figure 4(c1)). In anterior view, the upper margin of the medial condyle is clearly higher than the bony surface, forming a projecting edge (Figure 4(c2)). In distal view, the medial condyle strongly extends posteriorly, the posterior end of which greatly exceeds the anteroposterior midline of the medial epicondyle (Figure 4(c3)) [26].

In the woolly rhinos (genus Coelodonta), which were capable of living in alpine and cold zones, the distal extremity of the humerus is quite different to that of the Lunbori specimen. First, their sizes differ greatly, the diameter of the medial condyle of the distal trochlea is $98 \mathrm{~mm}$ in the smaller C. nihowanensis [27], and $119 \mathrm{~mm}$ in the Late Pleistocene $C$. antiquitatis [28], both of which are much larger than the Lunbori specimen, which is $67.5 \mathrm{~mm}$. Second, with regards to morphology, the collateral ligament fossa is indistinct on the medial surface of the distal extremity of the woolly rhino's humerus, but the collateral ligament and superficial digital flexor muscle tubercles are well developed, both of which are close to and even fused to each other. The lower margin of the medial epicondyle is much higher than that of the medial condyle, between which there is a distance of about $20 \mathrm{~mm}[28,29]$.

\section{Discussion of age}

Plesiaceratherium was established as a genus based on some isolated teeth and limb bones found in Early Miocene strata at Shanwang in Linqu, Shandong Province, with $P$. gracile serving as the type species [30]. Later, additional materials of Plesiaceratherium were discovered from Shanwang, including many well preserved skeletons, complete skulls, and many teeth and limb bones, which allowed detailed observations of the characteristics of Plesiaceratherium $[31,32]$. Plesiaceratherium is a medium- to large-sized primitive acerathere rhinoceros with slender limb bones. Previously, Plesiaceratherium was found only in two localities in China, i.e. Shanwang in Linqu, Shandong Province, and Jiulongkou in Cixian, Hebei Province [33]. In addition, Plesiaceratherium is distributed in Europe at five localities, Sandelzhausen (MN 5) and Voggersberg (MN 5) in Germany, Pont du Manne (MN 4) in France, Charneca de Lumiar (MN 4) in Portugal, and Can Julia (MN 4) in Spain [1].

The Chinese Shanwang and Jiulongkou faunas bearing Plesiaceratherium were determined to be from the late Early Miocene Shanwangian Age, and the European fossil localities bearing Plesiaceratherium belong to $\mathrm{MN} 4-5$ in the late Early Miocene Orleanian Age [1], which corresponds to the age of Plesiaceratherium in China.

Since the Mesozoic and Cenozoic strata in the Linqu Depression, in which the Shanwang area is located, are a series of volcanic and sedimentary rocks, radiometric dating has been well established for this basin. The published data, which are relatively consistent with the age of the fossils, indicate that a diatomite with rich fossils has been reported

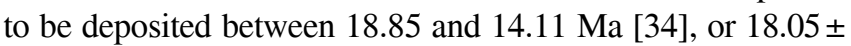
$0.55 \mathrm{Ma}$ [35]. In addition, because the samples were collected beneath the Shanwang Formation, the age of the Shanwang Fauna was about $18 \mathrm{Ma}$ [36]. The fossil locality of the Jiulongkou Fauna cannot be dated radiometrically, the locality includes several members of the Shanwang Fauna, such as Plesiaceratherium and Palaeomeryx, and also the younger Percrocuta [33]. Thus, its period should be the latest Shanwangian Age at about $16 \mathrm{Ma}$. The five localities bearing Plesiaceratherium in Europe belong to MN 4 or 5 of the mammalian ages at 18-15 Ma [37]. In conclusion, the localities in Plesiaceratherium's distribution in Eurasia are very close in age, i.e. the late Early Miocene.

Based on the Plesiaceratherium fossil found at the Lunbori locality in the Lunpola Basin, the upper part of the Dingqing Formation was deposited in the Miocene. Originally, and in general terms, the ostracod fossils of the Dingqing Formation were considered to be of Oligocene age $[4,13,14]$. However, the fossils from different layers or members should have different ages. The upper part of the Dingqing Formation, which is near the Plesiaceratherium layer, yield the ostracods Heterocypris formalis, Heterocypris subsinuatus, Candoniella albicans, Ilyocypris errabundis, Ilyocypris dunschanensis, and Limnocythere cinctura [4,38]. Among them, L. cinctura was found from the Yancheng Formation in Jiangsu Province [39], with an age corresponding to that of the Early Miocene Shanwang Formation [40]; I. dunschanensis appeared only in the Neogene. C. albicans and I. errabundis were distributed from the Paleogene to the Neogene [38]. A comprehensive correlation indicates that the ostracod assemblage in the upper part of the Dingqing Formation is characteristic of the Early Miocene. Because the lower part of the Dingqing Formation preserves extensive thick-beds of oil shale and fine clastic deposits, new evidence combined with the ostracod fossils, 
supports the opinion that the entire Dingqing Formation belongs to the Oligocene and Miocene [6].

\section{Estimation of paleo-altimetry}

The fossils of $P$. gracile appear in great numbers in the Shanwang Fauna in Linqu, Shandong Province. This species, together with Palaeomeryx tricornis and Lagomeryx colberti, are dominant forms with respect to individual numbers in the fauna. In addition to rich mammalian fossils, the Shanwang locality also produced fossils of fishes, amphibians, reptiles, birds, insects, large plants, sporopollens, and algae. Thus, the habitat of Plesiaceratherium can be reconstructed rather accurately. The mammals from Shanwang are mainly forms that lived on the forest edge and in swampy areas, especially P. tricornis, L. colberti, and various squirrels (Tamiops asiaticus, Sciurus lii, Oriensciurus linquensis, and Plesiosciurus aff. sinensis) [41]. However, forms that lived in grasslands are rare, which indicates that the ecosystem was a subtropical or warm temperate forest during that time. Judging from the flora in Shanwang Basin, many species are subtropical evergreen or deciduous broadleafed plants, which also indicate a warm and humid climate $[31,42]$. The central area of Shandong Peninsula, where Shanwang of Linqu is located, has an elevation of less than $1000 \mathrm{~m}$, and the ecosystems of the Shanwang Fauna imply that the elevation during the Early Miocene was similar to the modern one. The distribution of Plesiaceratherium in Europe also was at a lower elevation $(<1000 \mathrm{~m})$, where the Early Miocene ecosystem flourished in a warm and humid climate between 18-16.5 Ma [43]. Thus, we can conclude that Plesiaceratherium was a rhinoceros that preferred warm and humid conditions and lived in subtropical or warm temperate forests.

A detailed sporopollen analysis of the Dingqing Formation [3] showed that the lower part had an Ulmus-Salix assemblage. We also recently found leaf fossils of Salix in the Dingqing Formation, which is consistent with sporopollen data. In the middle part, angiosperm pollen was more plentiful than gymnosperm pollen, accounting for 55\%$73 \%$ of the total amount. Thus, angiosperm plants were abundant, dominated by northern temperate deciduous broadleaf trees, among which Quercus, Salix, and Juglans were the most common. They were the main tree species of that time. The conifers primarily included Pinus, Picea, and Abies, which were secondary forest components. Herbaceous plants began to further develop. In the upper part, angiosperm pollen dominated the assemblage, accounting for $88 \%-91 \%$, and gymnosperm pollen was less abundant. Salix pollen rapidly increased, becoming the dominant species along with Quercus in this assemblage, and Rhus pollen also was abundant. Other woody plants included Juglans, Betula, Celtis, Magnolia, Acer, Corylus, Carya, and Pterocarya. The sporopollen assemblage of the Dingqing For- mation is similar to that of the Shanwang Formation in Linqu, Shandong Province, reflecting the warm and humid climate at that time [3]. The melanic deposits are well developed in the Dingqing Formation, which indicates a humid climate or environment during that time [44,45]. In summary, the rhino Plesiaceratherium lived in a warm and humid habitat similar to those in Shandong Province and Western Europe during the Early Miocene.

As mentioned above, paleo-altimetry estimates for the Lunpola Basin during the time of deposition of the Dingqing Formation are very different, ranging from about $1000 \mathrm{~m} \mathrm{[7]}$ to $4500 \mathrm{~m}$ [8]. Based on a direct comparison, elevations of the distribution of Plesiaceratherium in Shandong Province and Western Europe support a paleo-altimetry estimation of about $1000 \mathrm{~m}$ in the Lunpola Basin during that time. However, a more reasonable estimate must be determined for the highest limit of subtropical or warm temperate forests given the global climatic and environmental conditions during the Early Miocene.

The distribution of animals and plants on the southern slope of the Himalaya Mountains along the southern border of the Tibetan Plateau has distinct vertical zones. In this area, the upper limit of the evergreen broad-leaf forest is $2500 \mathrm{~m}$ a.s.l. with a warm and humid climate, an annual rainfall of about $2000 \mathrm{~mm}$, and varied taxa of animals with large populations [46]. Based on animal and plant characteristics, the habitat of the Shanwang Fauna bearing Plesiaceratherium and the Lunpola Plesiaceratherium were similar to this kind of evergreen broad-leaf forest.

Given this global climatic background, the rhino Plesiaceratherium lived between the two cooling events of Mi$\mathrm{lb}$ at $17.8 \mathrm{Ma}$ and $\mathrm{Mi}-2$ at $16 \mathrm{Ma}$ [47], but the temperature during that time was higher than that of the modern levels [48]. In fact, the historic temperature was $4^{\circ} \mathrm{C}$ higher than modern temperatures (calculated from oxygen isotopes [49]). The distribution of vertical vegetation zones is directly related to atmospheric temperature, with a temperature lapse rate of $0.6^{\circ} \mathrm{C} / 100 \mathrm{~m}$ [50]. As a result, a temperature increase of $4^{\circ} \mathrm{C}$ would drive the boundaries of the vertical vegetation zones about $670 \mathrm{~m}$ higher. Thus, during the Early Miocene, the evergreen broad-leaf forest that was suitable for Plesiaceratherium would have been at a maximum elevation of $3170 \mathrm{~m}$.

In modern times, species of the Rhinocerotidae are still distributed in South Asia on the south side of the Tibetan Plateau, including Nepal where the Indian rhino (Rhinoceros unicornis) lives in forest and grassland areas at the foot of the Himalayas. Among extant rhinoceroses, the Sumatran rhino (Dicerorhinus sumatrensis) can live in tropical rain forests at elevations of 1000-1500 m because of its hairy coat [51]. The highest distribution of the Javan rhino (Rhinoceros sondaicus) was recorded at $2000 \mathrm{~m}$ a.s.1. [52]. Given this optimum ecological range for the extant rhinoceroses, and through an elevation adjustment of $670 \mathrm{~m}$ derived by a temperature lapse rate [50] of $4^{\circ} \mathrm{C}$ higher in the 
Early Miocene [49], the maximum paleo-altimetry of Plesiaceratherium's habitat during the Early Miocene in the Lunpola Basin should be close to $3000 \mathrm{~m}$ a.s.1.

\section{Conclusions}

The age of Cenozoic deposits in the Lunpola Basin in northern Tibet has been disputed for a many years, primarily because of a lack of fossils with accurate chronological significance. The distal extremity of a rhinocerotid humerus from the upper part of the Dingqing Formation at the Lunbori locality in Baingoin County is the first mammalian fossil found in the Cenozoic deposits of the Lunpola Basin. Our detailed observations and comparisons show that its medial condyle is wide at the bottom and narrow at the top, the medial collateral ligament fossa is relatively shallow, and the medial collateral ligament tubercle is very weak. The medial part of the upper margin of the medial condyle smoothly connects to the bony surface above, but lacks a clear boundary between them, which indicates that this specimen was Plesiaceratherium sp. of the Rhinocerotidae.

Plesiaceratherium has previously been found in eastern China and Western Europe, and the strata bearing this rhino's fossils in the two regions have been correlated to the late Early Miocene. Radiometric dating for the Shanwang Basin in Linqu County, Shandong Province indicates that Plesiaceratherium lived between 18-16 Ma. Thus, the upper part of the Dingqing Formation bearing the Plesiaceratherium fossil was deposited during the late Early Miocene, and the entire Dingqing Formation included OligoceneMiocene deposits.

The vegetation type of the Dingqing Formation was identical to that of the Shanwang Fauna and Plesiaceratherium has been inferred to live in subtropical and warm temperate forests, preferring a warm and humid climate. The correlations and adjustments based on modern alpine vegetation vertical zones in the Himalayas and the Early Miocene global climatic conditions indicate that the highest elevation in the Lunpola Basin at the time of the deposition of the Dingqing Formation could not have exceeded $3170 \mathrm{~m}$ a.s.l. Thus, considering the ecological requirements of rhinoceroses through a paleo-temperature adjustment for the Early Miocene, the most reasonable paleo-elevation for Plesiaceratherium is close to $3000 \mathrm{~m}$ a.s.l.

We appreciate the support and cooperation of Prof. Ding Lin of the Institute of Tibetan Plateau Research, Chinese Academy of Sciences (CAS), Prof. Sun Jimin and Prof. Liu Qingsong of the Institute of Geology and Geophysics, CAS, and Dr. Zhao Min, Dr. Wu Feixiang, Dr. Wang Ning, Mr. Shi Fuqiao, and Wu Shengli of the Institute of Vertebrate Paleontology and Paleoanthropology, CAS, for their assistance during field work. We are also grateful for constructive comments from the reviewers of this manuscript. This work was supported by the Knowledge Innovation Program of the Chinese Academy of Sciences (KZCX2-YW-Q09), the National Basic Research Program of China (2012CB821906), and the National Natural Science Foundation of China (40730210).
1 Heissig K. Family Rhinocerotidae. In: Rössner G E, Heissig K, eds. The Miocene Land Mammals of Europe. München, Verlag Dr. Friedrich Pfeil, 1999. 175-188

2 Kahlke R D. The History of the Origin, Evolution and Dispersal of the Late Pleistocene Mammuthus-Coelodonta Faunal Complex in Eurasia (Large Mammals). Rapid City: Fenske Companies, 1999. $1-219$

3 Wang K F, Yang J W, Li Z, et al. On the Tertiary sporopollen assemblages from Lunpola Basin of Xizang, China and their palaeogeographic significance (in Chinese). Sci Geol Sin, 1975, (4): 366-374

4 Xia W G. Ostracoda fauna from Lunpola Group in Xizang (Tibet) and its geological age (in Chinese). Contr Geol Qinghai-Xizang (Tibet) Plateau, 1982, 4: 149-159

5 Xia W G. Some charophytes from Lunpola Group in Lunpola Basin, Baingoin County, Xizang (Tibet) (in Chinese). Bull Chengdu Inst Geol M R, Chin Acad Geol Sci, 1986, 7: 61-67

6 Xia J B. Cenozoic of Baingoin and its bordering, Xizang (Tibet) (in Chinese). Contr Geol Qinghai-Xizang (Tibet) Plateau, 1983, 6: 243-254

7 Ma X D. A discussion of some problems of stratigraphy in central Tibet (in Chinese). Geol Bull Chin, 2003, 22: 695-698

8 Rowley D B, Currie B C. Palaeo-altimetry of the Late Eocene to Miocene Lunpola Basin, central Tibet. Nature, 2006, 439: 677-681

9 Wu Y F, Chen Y Y. Fossil cyprinid fishes from the late Tertiary of north Xizang, China. Vert PalAsiat, 1980, 18: 15-20

10 Lei Q L, Fu X Y, Lu Y P. Petroleum geological features of Tertiary terrestrial Lunpola Basin, Xizang (Tibet) (in Chinese). Earth Sci, J Chin Univ Geosci, 1996, 21: 168-173

11 Li P. Preliminary knowledge for the geology of eastern Tibet (in Chinese). Chinese Sci Bull, 1955, (7): 62-71

12 Qu Y G, Wang Y S, Duan J X, et al. Regional Geological Report of Duoba Map of the People's Republic of China (in Chinese). Wuhan: China University Geoscience Press, 2011

13 Bureau of Geology and Mineral Resources of Xizang Autonomous Region. Stratigraphy (Lithostratic) of Xizang Autonomous Region (in Chinese). Wuhan: China University Geoscience Press, 1997. 1-302

14 Zhang K X, Wang G C, Ji J L, et al. Paleogene-Neogene stratigraphic realm and sedimentary sequence of the Qinghai-Tibet Plateau and their response to uplift of the plateau. Sci China Earth Sci, 2010, 53: 1271-1294

15 Zheng S H. The Hipparion fauna of Bulong Basin, Biru, Xizang (in Chinese). In: The Comprehensive Scientific Expedition to the QinghaiXizang Plateau, the Chinese Academy of Sciences, ed. Palaeontology of Xizang, Book 1. Beijing: Science Press, 1980. 33-47

16 Gromova B. Identification Key of Mammalian Large Limb Bones (translated by Liu H Y, et al.). Beijing: Science Press, 1961. 1-162

17 Sission S, Grossman J D. The Anatomy of the Domestic Animals. 4th ed. Philadelphia: W. B. Saunders Company, 1953. 1-972

18 Coombs M C. Reevaluation of Early Miocene North American Moropus (Perissodactyla, Chalicotheriidae, Schizotheriinae). Bull Carnegie Mus Nat Hist, 1978, 4: 1-62

19 Coombs M C. Tylocephalonyx, a new genus of North American dome-skulled chalicotheres (Mammalia, Prrissodactyla). Bull Amer Mus Nat Hist, 1979, 164: 1-64

20 Osborn H F. The titanotheres of ancient Wyoming, Dakota, and Nebraska. US Geol Surv Monogr, 1929, 55: 1-894

21 Wang B Y. Osteology and phylogenetic relationship of Rhinotitan mongoliensis. Mem Inst Vert Paleont Paleoanthrop, Acad Sin, 1982, 16: $1-75$

22 Prothero D R, Schoch R M. Classification of the Perissodactyla. In: Prothero D R, Schoch R M, eds. The Evolution of Perissodactyls. New York: Oxford University Press, 1989. 530-537

23 Wang J W. A new genus of Forstercooperiinae from the Late Eocene of Tongbo, Henan. Vert PalAsiat, 1976, 14: 104-111

24 Qiu Z X, Wang B Y. Paracerathere fossils of China. Palaeont Sin, 2007, 29: 1-396

25 Xu Y X. Amynodonts of Inner Mongolia. Vert PalAsiat, 1966, 10: 123-190

26 Deng T. Limb bones of Chilotherium wimani (Perissodactyla, Rhi- 
nocerotidae) from the Late Miocene of the Linxia Basin in Gansu, China. Vert PalAsiat, 2002, 40: 305-316

27 Deng T. Comparison between the woolly rhino's forelimbs from Longdan, northwestern China and Tologoi, Transbaikalian region. Quat Int, 2008, 179: 196-207

28 Hsu Y H, Chou P H, Lee Y C. Pleistocene mammalian fossils from the northeastern provinces, Rhinocerotidae. Mem Inst Vert Paleont Paleoanthrop Acad Sin, 1959, 3: 45-49

29 Borsuk-Bialynicka M. Studies on the Pleistocene rhinoceros Coelodonta antiquitatis (Blumenbach). Palaeont Pol, 1973, 29: 1-94

30 Young C C. On a Miocene mammalian fauna from Shantung. Bull Geol Soc China, 1937, 17: 209-238

31 Yan D F. Über die Klassifikation und Morphologie des Schädel von Plesiaceratherium. Vert PalAsiat, 1983, 21: 134-143

32 Yan D F, Heissig K. Revision and autopodial morphology of the Chinese-European rhinocerotid genus Plesiaceratherium Young, 1937. Zitteliana, 1986, 14: 81-109

33 Chen G F, Wu W Y. Miocene mammalian fossils of Jiulongkou, Cixian district, Hebei. Vert PalAsiat, 1976, 14: 6-15

34 Jin L Y. K-Ar ages of Cenozoic volcanic rocks in the middle segment of the Tancheng-Lujiang fault zone and stages of related volcanic activity (in Chinese). Geol Rev, 1985, 31: 309-315

35 Chen D G, Peng Z C. K-Ar ages and $\mathrm{Pb}, \mathrm{Sr}$ isotopic characteristics of Cenozoic volcanic rocks in Shandong, China (in Chinese). Geochimica, 1985, (4): 293-303

36 Deng T, Wang W M, Yue L P. Recent advances of the establishment of the Shanwang Stage in the Chinese Neogene. Vert PalAsiat, 2003, 41: 314-323

37 Steininger F F. Chronostratigraphy, geochronology and biochronology of the Miocene "European Land Mammal Mega-Zones" (ELMMZ) and the Miocene "Mammal-Zones (MN-Zones)". In: Rössner G E, Heissig K, eds. The Miocene Land Mammals of Europe. München, Verlag Dr. Friedrich Pfeil, 1999. 9-24

38 Hou Y T, Gou Y X, Chen D Q. Ostracod Fossils of China, Vol. I, Cypridacea and Darwinulidacea (in Chinese). Beijing: Science Press, 2002. 1-1090

39 Hou Y T, Gou Y X. Ostracod Fossils of China, Vol. II, Cytheracea and Cytherellidae (in Chinese). Beijing: Science Press, 2007. 1-798

40 Zhen J J, He X X, Liu S W, et al. Chinese Stratigraphical Lexicon, Tertiary (in Chinese). Beijing: Geological Publishing House, 1999. $1-163$

41 Qiu Z D, Yan C L. New sciurids from the Miocene Shanwang Formation, Linqu, Shandong. Vert PalAsiat, 2005, 43: 194-207

42 Tao J R, Sun B, Yang H. The flora of the Shanwang Formation (in Chinese). In: Sun B, ed. Plant Fossils from Shanwang. Jinan: Shandong Science and Technology Press, 1999. 13-89

43 Böhme M. The Miocene Climatic Optimum, evidence from ectothermic vertebrates of Central Europe. Palaeogeogr Palaeoclimatol Palaeoecol, 2003, 195: 389-401

44 Ma L X, Zhang E H, Ju J C, et al. Basic characteristics of Paleogene deposition systems tract in Lunpola Basin, Xizang (Tibet) (in Chinese). Earth Sci, J China Univ Geosci, 1996, 21: 174-178

45 Du B W, Tan F W, Chen M. Sedimentary features and petroleum geology of the Lunpola Basin, Xizang (in Chinese). Sediment Geol Tethyan Geol, 2004, 24: 46-54

46 Qian Y W, Feng Z J, Ma L L. Faunal surveys of birds and mammals in the Mount Qomolangma area (in Chinese). In: The Scientific Expedition to Tibet, the Chinese Academy of Sciences, ed. Reports of the Scientific Expedition to the Mount Qomolangma Area, 1966-1968, Biology and Alpine Physiology. Beijing: Science Press, 1974. 1-23

47 Wang P X, Zhao Q H, Jian Z M, et al. Thirty million year deep-sea records in the South China Sea. Chinese Sci Bull, 2003, 48: 2524-2535

48 Zachos J, Pagani M, Sloan L, et al. Trends, rhythms, and aberrations in global climate 65 Ma to present. Science, 2001, 292: 686-693

49 Pekar S F, DeConto R M. High-resolution ice-volume estimates for the Early Miocene, evidence for a dynamic ice sheet in Antarctica. Palaeogeogr Palaeoclimatol Palaeoecol, 2006, 231: 101-109

50 Wang X P, Zhang L, Fang J Y. Geographical differences in alpine timberline and its climatic interpretation in China (in Chinese). Acta Geogr Sin, 2004, 59: 871-879

51 Groves C P, Kurt F. Dicerorhinus sumatrensis. Mammal Spec, 1972, 21: $1-6$

52 Foose T J, van Strien N. Asian Rhinos, Status Survey and Conservation Action Plan. Gland, IUCN, 1997. 1-112

Open Access This article is distributed under the terms of the Creative Commons Attribution License which permits any use, distribution, and reproduction in any medium, provided the original author(s) and source are credited. 